\title{
Keeping with the Global Trends: An Evaluation of Accessibility and Usability of Nigerian Banks Websites
}

\author{
${ }^{1}$ Ishaq O. Oyefolahan, ${ }^{2}$ Aishat A. Sule, ${ }^{2}$ Solomon A. Adepoju, ${ }^{1}$ Faiza Babakano \\ ${ }^{1}$ Department of Information and Media Technology, \\ ${ }^{2}$ Department of Computer Science \\ School of Information \& Communication Technology, Federal University of Technology Minna \\ Email: o.ishaq@futminna.edu.ng, suleaishat990@gmail.com, solo.adepoju@ futminna.edu.ng, \\ faiza.bkano@futminna.ed.ng
}

Received: 07 March 2018; Accepted: 20 January 2019; Published: 08 March 2019

\begin{abstract}
The growing need for accessible websites cannot be overemphasized as it has posed a major challenge in the world of Information and Communication Technology (ICT). Most businesses have gone online in order to improve their market value; the banking sector is not an exception. In an attempt to satisfying customers, websites developers have violated most of the websites standards. The banking sector is one area that carries out most of its activities online. Therefore, it is important that their websites be accessible to all especially people with visually impaired disability and more so, regardless of the browsing technology being used. This study evaluates the accessibility and usability of Nigeria banking websites using some automated tools and manual inspection method. This is done in order to know the conformance of the banking websites with standard as specified by Web Accessibility Initiate (WAI). Results from the study indicate that some of the websites do not conform to the expected standard. Hence, there is need for substantial improvements on most bank websites in Nigeria
\end{abstract}

Index Terms-Website, Accessibility, Usability, Nigeria, Website Evaluation Tools, Bank websites.

\section{INTRODUCTION}

Over the years, proliferation of the internet has led to technologies adoption by banks to develop websites so that customers can easily carry out transactions. Apparently, every viable bank aims to achieve tremendously well in the market hence there is need to ensure that their banking website is accessible and usable $[1,2]$. Website usage in today's business world knows no bound and this can be beneficial in improving productivity and streamlining processes. However, if the customers and visitors do not find the website easy to use, they will not carry out the expected transaction and this may lead to loss of money which may negatively impact the business [3]. Therefore, it is paramount an essential for banks to have an accessible and usable websites to ensure good quality service delivery $[4,5]$. In Nigeria it is reported that $42 \%$ of bank customers used online banking platforms to carry out one or more banking transactions while $77 \%$ used the social media. [6]. Though the figure is still low, however there is significant increase as compared to previous years when banking operation were not online.

It has been pointed out that usability and accessibility are among the vital factors in website development $[7,8]$. Users of the internet are on the increase and organizations are moving towards online delivery of products or services which is normally carried out on a website. Hence, for an effective online delivery of products or services, users of the websites must find them usable and accessible at all times. This will lead to increase in customers' satisfaction and consequently increase in market sales [9]. In this dispensation, a bank is inoperable without a functional website, hence the need arises to have a website that is both accessible and usable.

World Wide Web Consortium [10] defines accessibility on the Web as "an attribute by which people with disabilities can perceive, understand, navigate, and interact with the web, and they can contribute to the web." Based on this definition, accessibility is aimed at eliminating any form of limitations encountered by people having any type of disability. These may include people with visual, auditory, physical, speech, cognitive, and neurological disabilities in order to make the content on the Web accessible to anyone.

With good website accessibility in place, the opportunity for banks to connect to a large number of people with abilities and disabilities increases. Obviously, these people form a significant market segment that is essential for business growth. Transforming business and adapting technology to meet the need of people with disabilities leads to promotion of business. This will ultimately lead to significant improvement in investment of money, time and resources. Persons with abilities also have needs to be met; as such every design should be geared towards catering for the needs of every customer (both with abilities and disabilities) of a bank. 
On the other hand, usability is defined by the International Standards organization's ISO 9241 standard [11] as "the extent to which a product can be used by specified users to achieve specified goals with effectiveness, efficiency, and satisfaction in a specified context of use [11] The prerequisite for a firm's success at the strategic level is website usability because users of a website cannot be attracted to a site unless they can navigate the website easily $[12,13]$. As a result of this, a lot of pressure is being put on website developers to improve usability since users are presented with abundance of service choice and the ease to leave a website with just a click.

In this paper, the banking websites are evaluated based on accessibility and usability since most financial transactions are being done through online banking nowadays. The evaluation focused on top ten bank websites out of the twenty-two commercial banks in Nigeria.

\section{i) Accessibility Guidelines}

The Web has gradually an important resource in many facets of life in the contemporary era. Its usefulness is visible in education, government, commerce, health care, recreation and agriculture sectors among others. It is very crucial that the Web be accessible in order to provide equal opportunity and access to people with disability. There are standards that a website must conform to in order to be considered accessible - the accessibility guidelines. Web Content Accessibility Guidelines (WCAG) 2.0 refers to a wide range of recommendations for making Web content more accessible.

WCAG 2.0 is based on four central principles which are: perceivable, operable, understandable, and robust. The fundamental framework for ensuring content accessibility are provided by some specific guidelines which are covered by these four principles. There are total of twelve guidelines, which are based on a set of well-defined and testable criteria used in measuring accessibility conformance. They are rated either as A, AA, or AAA, with AAA having the highest level. The rating is to ensure the fulfilment of the accessibility requirements for different circumstances [10,14]. Furthermore, the guidelines provided by WCAG 2.0 are very informative and technical, with each defining three tiers of accessibility. Each guideline also has a set of checkpoints that web developers can use in order to ensure that different types of users will have easy access to their websites.

\section{ii) Usability Guidelines}

A significant part of a website's success is its ease of use, or simply its usability, especially with websites becoming more and more complex and interactive. Usability is essential to create an effective web presence. To design a usable system involves far more than mere application of guidelines. However, significant contributions can still be made through guidelines to usability by promoting consistency and good practice.
Over the years, there have been development of various website usability guidelines and yet there is currently no guideline set that has been established as a standard guiding framework [1]. Early collections of usability guidelines contained over one thousand rules to follow consequently, a much smaller list of nine principles were presented by [15]. Some principles of good design according to [16] are as follows: the use simple and natural dialogue, speaking of the user's language, minimising memory load, consistency, provision of feedback, providing clearly marked exits, provision of shortcuts, provision of good error messages and prevention errors in the first place.

\section{RELATED WORKS}

Over the years, several studies on website evaluation have been carried out, most of which are geared towards accessibility and usability. There are variety of methods for evaluating user interfaces [18]. Researchers have evaluated websites from functionality, navigation, quality, accessibility and usability points of view $[19,20,21,22,23]$. Recently, the use of automated tools in carrying out the evaluation have gained tremendous popularity [24.25],.

There is a high usage of the web especially in Nigeria due to the availability of tablets, PCs, and mobile devices which comes in handy. With these devices and access to the internet, the disabled find it difficult to access much of the information on website due to lack of accessibility. The same is applicable even to people without disabilities, who are also constantly faced with usability issues [26]. Research has shown that the most websites are not providing adequate levels of accessibility to both able and disabled persons [27]. The success of any banks are most often hampered by inaccessibility; whether offline or online. A bank's website cannot be usable if it is not accessible. [28] conducted a research which shows that usability is a measure of accessibility hence; accessibility should be given utmost importance.

[29] proposed and tested a model known as the Web Assessment Index (WAI), which was used to evaluate the quality of e-banking websites. Four criteria of speed, website content, navigability and accessibility were used in the study. The results from the study show that there was demonstration of high level of flexibility of WAI by Spanish banks. They also detected the main weaknesses of the web pages assessed. [26] also evaluated the accessibility of Indian banking website using the conformance method and deduced that all the website had one or more accessibility issues which implies that none of the websites were accessible.

[30] explored the accessibility level of banking and financial systems for blind users in USA. It was reported that several of the websites used in the study did not totally conform to accessibility standard. As a result, a high percentage of the participant reported accessibility problems. In Brazil, a study was conducted to evaluate the functionality, reliability and usability of quality of 
user interaction with the internet banking website in the country [19]. [31] had in their study evaluated the websites of banks in Pakistan by using automated tools based on W3C web accessibility standards. The tools used are functional accessibility evaluator and total validator. Results obtained also showed that most websites were not built according to Standard accessibility rules.

Several ways of evaluating website accessibility include user testing, subjective assessment, screening technique, conformance review and barrier walk-through. Two critical components as stated by [18] are essential in determining website usability: Ease of use and Navigation [20] .

In addition, [32] is of the opinion that usability improvement is related to navigation, link appearance, and the provision of more positive features like search boxes and breadcrumb trails.. Web usability research covers the work of [1] which utilized user heuristic evaluation method by using eight website users as evaluators and employing the instrument developed by [33] to determine the usability of all banks in Taiwan. Web navigability structure of India e- banking websites was investigated by [34]. This is to know the ease at which users can move from one content to another using hyperlink within the websites. The study found out there was significant difference between the navigation of websites in public and private. The popularity and importance of the websites were also tested using Google page rank and Alexa rank. Other studies that involve the use of automated tools in other websites domains are as follows; [35] study involves the use of two automated tools; site analyzer and qualidator tool to evaluate the universities of Punjab website to find out their usability level. The need to incorporate accessibility and usability criteria into products applications and design was emphasized in the study to investigate the accessibility and usability of Malaysian higher education website [36]. Automated tools were used to evaluate academic websites in Nigeria by [28]. In the study, website accessibility checker, WAVE and HERA were used for the evaluation and the result showed that all the websites were not in compliance with WCAG.

Another usability guideline developed by Nielson [15] to upload speed and page size of the main page and broken links existence was being adopted for evaluating the usability of banking websites. Conformance review method using automated tool and manual inspection was adopted in this study.

\section{Methodology}

The methods adopted in this study involve sampling of websites from list of commercially active banks in Nigeria to the evaluation approaches used in assessing the websites. Each of these approaches are further described below.

\section{i) Sampling}

Out of twenty-two commercial banks in Nigeria, ten were purposefully selected on the basis that they were the best top ten. Table 1 shows the list of the ten banks along with their URL and abbreviations. Subsequently, their abbreviations as represented in this paper shall be used for the purpose of clarity.

The evaluation method used is the Conformance review which is an analytical method that is based on standards and/or guidelines. It also includes computer-aided testing with accessibility tools. The key set of guidelines for assessing the accessibility of websites is the WCAG developed by the Web Accessibility Initiative (WAI) [37].

Table 1. Sample banks in Nigeria

\begin{tabular}{llll}
\hline S/N & BANKS & Abbreviation & \multicolumn{1}{c}{ URL } \\
\hline 1 & First Bank & FBN & www.firstbanknigeria.com \\
2 & Union Bank & UBN & www.unionbankng.com \\
3 & Zenith Bank & ZB & www.zenithbank.com \\
4 & Diamond Bank & DB & www.diamondbank.com \\
5 & Access Bank plc & AB & www.accessbankplc.com \\
6 & Ecobank & EB & www.ecobank.com \\
7 & United Bank of Africa & UBA & www.ubagroup.com \\
8 & Skye Bank & SB & www.skyebankng.com \\
9 & Guaranteed Trust Bank & GTB & www.gtbank.com \\
10 & Fidelity Bank & FB & www.fidelitybank.ng \\
\hline
\end{tabular}

The first version, WCAG 1.0 was published in 1999 [38] while the second version known is known as WCAG 2.0 [39]. Both versions are expected to be used in parallel for some time. A quality website must conform to these standards to be considered usable and accessible.
Automated tools such as European Internet Inclusion Initiative (EIII) Tool [40], Wave tool [41] and Achecker tool [42] were used to evaluate the accessibility. Since usability is a measure of accessibility, attention was focused more on accessibility. The usability evaluation was done using Pingdom Website Speed Test [43] in 
order to evaluate the uploaded speed and page size of the main page. GooglePageSpeedInsight [44] was used to check for the performance optimization and webpageFX [45] for readability test. In addition, W3C Link checker [46] was used to check for broken link from the websites. The strategies described below were adopted in checking for the accessibility of the banking websites.

\section{ii) Graphical browser testing}

The Mozilla Firefox Web browser was used to visit each of the 10 banks' home pages by following these steps:

To test for alternatives text provision for non-text content, the home page images were turned off by the use of Firefox Web Developer Extension software [47]. This is to know whether the alternate text was both accessible and proper. The home page font sizes were also altered in order to see if variation effect caused any decomposition or distortion in the page.

Furthermore, home pages of each of the banks' website was also viewed using different screen resolutions: $1024 \times 768,1280 \times 800 ; 1280 \times 1024 ;$ and $800 \times 600$ $[48,49]$ and $1366 \times 768$, which is the dominant resolution [50]. They were examined at each resolution to determine whether they fit within the screen without the need for horizontal scrolling.

Colorblind Web Page Filter by [51] was also used to change colors to the gray scale to test the websites with people who have color blindness . This is to know whether they are able to perceive and check if everything on the page was still clearly visible.

Other disabled users especially those with mobility impairments who cannot use a mouse also require the ability to navigate the web only through the keyboard [10]. Each home page was also tested to check for possibility of navigating through all the links using only the Tab key on the keyboard.

\section{iii) Text-only browser testing}

The Lynx browser which is a text-only browser was used to test each home pages of the bank. During the test, Lynx was used to check for the availability of all information contained within the page and to ensure that it is visible with a graphical browser. It further checks that it was in a format that was both readable and understandable. This verbalizes content for those with visual impairments and it is a useful check on the accessibility of Web pages in practice [52]

\section{iv) Automated Testing}

The different automated tools used to determine the accessibility features of the websites include European Internet Inclusion Initiative (EIII) Tool, Wave and the Achecker tool. Though these tools cannot adequately measure accessibility, they are able to provide some clues into accessibility related problems. They provide data about whether an image has ALT text but cannot check the validity of the text itself. However, when combined with other methods, the overall evaluation process is improved and is easy to determine if a website meets accessibility guidelines or not [53]. Despite the various evaluation tools listed by the W3C [53], Achecker tool has been the most widely used for evaluation.

\section{v) Mobile friendly testing.}

The use of mobile devices in the current technological advancement has increased greatly. Mobility devices such as apple IPad and Samsung are now of most preference among computing devices because of its portability. As such there is need to evaluate a websites' mobile friendliness to ensure that a website render as well on mobile devices as they would on other platforms. The banks' websites were examined using Google's mobile-friendly test [54] which analyses a given URL and then check the degree to which its design is mobile-friendly.

\section{ANALySIS OF RESUlts}

The results of the evaluation test on the banks' websites are presented as follows

\section{i) Mobile-friendly test}

Considering the fact that mobile penetration in Nigeria is one of the highest in the world and most customers would in most of the times want to access their bank websites via mobile platform; the mobile friendly test was conducted.

The mobile-friendly test was found to be considerably appropriate in the sense that $70 \%$ (7 out of 10) of the bank's websites passed the test. At the time of carrying out the test, the websites of DB and GTB were not reachable and UBN was rated not mobile-friendly. Table 2 depicts the final result after carrying out the mobile-friendly test on the websites.

Table 2. Mobile-friendly test result

\begin{tabular}{ll}
\hline BANKS & MOBILE-FRIENDLINESS \\
\hline FBN & Mobile-Friendly \\
UBN & Not Mobile-Friendly \\
ZB & Mobile-Friendly \\
DB & Not-Recheable \\
AB & Mobile-Friendly \\
EB & Mobile-Friendly \\
UBA & Mobile-Friendly \\
SB & Mobile-Friendly \\
GTB & Not-Recheable \\
FB & Mobile-Friendly \\
\hline
\end{tabular}

ii) Graphical browser test 
The various test conducted include testing the websites on various screen resolution; checking for alternative text on all images on the website; navigation; grey scale and checking if text size modification causes any distortion on the page's layout. Using Firefox extension, images were turned off to check for Alt text. $60 \%$ of the website scored poorly because there was no appropriate Alt text for all images. The other websites scored fairly because they had at least one or two images with appropriate Alt text especially their logo but none of the website had all images with Alt text hence, none had a good score.
To check if color blind users could access the websites, Toptal color blind webpage filter was used to change the color of the websites to grey. All the websites scored well in this category. To check if all links could be accessed using just the tab key and shift + tab; internet explorer was used to view all the websites. Only $10 \%$ of the website (i.e. FBN) had a good score. $20 \%$ scored poorly. $70 \%$ scored fairly because all the sub-links could not be accessed using just the keyboard. The results are depicted in tables 3 and 4.

Table 3. Result of the Graphical-browser test.

\begin{tabular}{lllll}
\hline BANKS & Images turned off & Gray-scale & No mouse & Font size change \\
\hline FBN & Poor & Good & Good & Poor \\
UBN & Poor & Good & Poor & Poor \\
ZB & Poor & Good & Poor & Poor \\
DB & Fair & Good & Fair & Poor \\
AB & Fair & Good & Fair & Poor \\
EB & Poor & Good & Fair & Poor \\
UBA & Poor & Good & Fair & Poor \\
SB & Fair & Good & Fair & Poor \\
GTB & Poor & Good & Fair & Poor \\
FB & Fair & Good & Fair & Poor \\
\hline
\end{tabular}

Table 4. Result of the screen resolution test.

\begin{tabular}{|c|c|c|c|c|c|}
\hline BANKS & $800 \times 600$ & $1366 \times 768$ & $1024 \times 768$ & $1280 \times 800$ & $1280 \times 1024$ \\
\hline FBN & Good & Poor & Good & Poor & Poor \\
\hline UBN & Good & Poor & Good & Poor & Poor \\
\hline $\mathrm{ZB}$ & Good & Poor & Good & Poor & Poor \\
\hline DB & Good & Poor & Good & Poor & Poor \\
\hline $\mathrm{AB}$ & Good & Poor & Good & Poor & Poor \\
\hline EB & Good & Poor & Good & Poor & Poor \\
\hline UBA & Good & Poor & Good & Poor & Poor \\
\hline SB & Good & Poor & Good & Poor & Poor \\
\hline GTB & Good & Poor & Good & Poor & Good \\
\hline FB & Good & Poor & Good & Poor & Poor \\
\hline
\end{tabular}

All the websites were good on two screen resolutions (i.e., $800 \times 600$ and $1024 \times 768$ ). While on the other resolutions they fared poorly meaning that on such resolutions, the websites will be too large to fit the screen and so would require horizontal scrolling. Only GTB had a good score on resolution 1280 x 1024 .

\section{iii) Automated test}

The results of the aforementioned tools are shown in Table 5. AChecker results indicate that SB had no accessibility issues. Others had several known problems (KP), likely problems (LP), and potential problems (PP) at various degrees. UBA had the highest KP. 
Table 5. The AChecker result.

\begin{tabular}{llll}
\hline BANKS & KP & LP & PP \\
\hline FBN & 26 & 1 & 518 \\
UBN & 290 & 0 & 759 \\
ZB & 7 & 0 & 442 \\
DB & 80 & 1 & 655 \\
AB & 58 & 0 & 1657 \\
EB & 101 & 3 & 867 \\
UBA & 518 & 1 & 812 \\
SB & 0 & 0 & 0 \\
GTB & 7 & 0 & 442 \\
FB & 116 & 0 & 444 \\
\hline
\end{tabular}

The EII tool tests to know if the XHTML elements of the webpage conform to standards as shown in table 6. The tool grades over 100 with a few test failed for score between 95 and 99; some test failed for score between 85 and 95; many test failed for score between 70 and 85 ; most test failed for score between 0 and 70; and 100 when a website fails no test. It appears from test that GTB failed most of the test while UBN, DB, and FB only failed some test. Many tests were failed by the rest of the banks. None of the banks' websites passed the test completely.

Table 6. The EII tool result.

\begin{tabular}{cccc}
\hline BANKS & Pass & Fail & Score \\
\hline FBN & 1353 & 58 & 78.17 \\
UBN & 971 & 86 & 89.90 \\
ZB & 1015 & 107 & 83.10 \\
DB & 633 & 109 & 87.42 \\
AB & 1660 & 41 & 72.11 \\
EB & 1300 & 63 & 80.45 \\
UBA & 892 & 98 & 72.66 \\
SB & 499 & 27 & 81.57 \\
GTB & 399 & 17 & 57.27 \\
FB & 815 & 25 & 86.87 \\
\hline
\end{tabular}

The report from the Wave tool in table 7 shows that UBA recorded the highest numbers of errors and alerts. While DB recorded the highest number of contrast error, SB recorded the least. Also, SB recorded the least number of contrast error and UBN had the least errors. GTB was not reachable (NR) at the time of the research.
Table 7. The Wave tool result.

\begin{tabular}{llll}
\hline BANKS & Errors & Alerts & $\begin{array}{l}\text { Contrast } \\
\text { Errors }\end{array}$ \\
\hline FBN & 31 & 43 & 5 \\
UBN & 17 & 26 & 6 \\
ZB & 82 & 44 & 12 \\
DB & 31 & 54 & 93 \\
AB & 44 & 51 & 22 \\
EB & 23 & 40 & 47 \\
UBA & 95 & 69 & 56 \\
SB & 21 & 6 & 1 \\
GTB & NR & NR & NR \\
FB & 29 & 36 & 9 \\
\hline
\end{tabular}

\section{iv) Text-only browser test}

In this category, all the websites scored poorly because none of the page was understandable on the Lynx browser, neither was all the information available nor was it readable. The result is shown in table 8 .

Table 8. Text-based result

\begin{tabular}{lll}
\hline BANKS & $\begin{array}{l}\text { Information } \\
\text { available }\end{array}$ & $\begin{array}{l}\text { Readable } \\
\text { understandable }\end{array}$ \\
\hline FBN & Poor & Poor \\
UBN & Poor & Poor \\
ZB & Poor & Poor \\
DB & Poor & Poor \\
AB & Poor & Poor \\
EB & Poor & Poor \\
UBA & Poor & Poor \\
SB & Poor & Poor \\
GTB & Poor & Poor \\
FB & Poor & Poor \\
\hline
\end{tabular}

\section{v) Usability Analysis}

The usability aspect takes into account the readability, optimization, broken links, load time, and page size of each of the websites. The evaluation showed that the optimization of most of the websites is low and there is likelihood of a slow user experience. The websites that had a fair score indicate that the pages are missing some common performance optimizations that may result in a slow user experience. Only Union Bank had a good score. 
In terms of broken links, all the websites have the existence of broken links except Ecobank.40\% of the sample website had a load time greater than 10s. The page sizes are all above $34 \mathrm{~kb}$. Therefore, the websites cannot be considered usable and so requires improvement. The overall result is shown in table 9.

Table 9. Usability analysis

\begin{tabular}{lllll}
\hline BANKS & Page size & Load time & Optimization & $\begin{array}{l}\text { Broken } \\
\text { link }\end{array}$ \\
\hline FBN & $3.8 \mathrm{mb}$ & $3.15 \mathrm{~s}$ & Poor & Yes \\
UBN & $1.7 \mathrm{mb}$ & $4.20 \mathrm{~s}$ & Good & Yes \\
ZB & $11.0 \mathrm{mb}$ & $3.20 \mathrm{~s}$ & Fair & Yes \\
DB & $2.4 \mathrm{mb}$ & $10.01 \mathrm{~s}$ & Fair & Yes \\
AB & $21.5 \mathrm{mb}$ & $2.00 \mathrm{~s}$ & Poor & Yes \\
EB & $3.8 \mathrm{mb}$ & $6.26 \mathrm{~s}$ & Poor & No \\
UBA & $1.6 \mathrm{mb}$ & $10.16 \mathrm{~s}$ & Poor & Yes \\
SB & $2.8 \mathrm{mb}$ & $10.47 \mathrm{~s}$ & Poor & Yes \\
GTB & $8.7 \mathrm{mb}$ & $16.39 \mathrm{~s}$ & Poor & Yes \\
FB & $1.6 \mathrm{mb}$ & $6.33 \mathrm{~s}$ & Poor & Yes \\
\hline
\end{tabular}

The readability aspect evaluated all banks to be readable though to a certain age interval, this gives an insight into how readable the website is or how a document can be clearly understood. For banks whose website can be understood by people with age 14-15 implies that they are less readable than those whose website can be understood by people within age 12-13. Notwithstanding all the websites can be considered readable since the age range for people that could understand the website was still below the age of 18. All websites were available except SB website which could not be reached at the time of the research. The result is depicted in table 10 .

Table 10. Results of readability

\begin{tabular}{lll}
\hline Banks & $\begin{array}{l}\text { Average } \\
\text { level }\end{array}$ & gradeAge interval \\
\hline FBN & 8 & $13-14$ \\
UBN & 8 & $13-14$ \\
ZB & 8 & $13-14$ \\
DB & 7 & $12-13$ \\
AB & 9 & $14-15$ \\
EB & 7 & $12-13$ \\
UBA & 8 & $13-14$ \\
SB & N/A & N/A \\
GTB & 11 & $16-17$ \\
FB & 9 & $14-15$ \\
\hline
\end{tabular}

\section{CONCLUSION}

In the analysis so far, most of the websites have violated at least one of the website standards. It can be deduced therefore that the banking sector needs to pay more attention to developing websites that give customers easy accessibility and usability. Website developers most times do not want to jeopardize their chance of winning a contract and so do not go into discussing extensively with their customers how accessibility and usability is essential in web development; these customers in question may not be aware since they are not in the field and hence needs to be giving a proper orientation before signing any agreement to developing a website.

Majorly, banking in Nigeria is done online and the website evaluated shows that most of the banks are only concerned about just having a website and not minding its conformance to standards or probably do not know that a website conformance to standards goes a long way to improving customer service. Developers are often guilty in that they pay more attention to satisfying their customers rather than users of the website. This has led to considerably large amount of accessibility issues in most of these websites. On carrying out the evaluation, it has been found than none of the banks' websites is fully accessible or usable. The use of Alt text on images is always taken for granted by most developers as discovered from the study. Most of the websites evaluated were guilty of no Alt text which posed a challenge on accessibility.

The results of the evaluation indicate that the situation of website accessibility and usability of Nigerian banking websites is not very satisfactory due to errors reported by the automatic tools. Thus, it is recommended that banks include accessibility and usability awareness training as part of their training activities; this will help bank's website maintenance team to easily detect any non-conformance in their website. Also, developers need to focus more attention on designing websites to meet standards while taking into consideration the customer's needs and balancing both to avoid conflict.

Also, adequate awareness on accessibility standards among the developers and designers of website is necessary for easy website development, update and maintenance. The designers as well as government should look into this for equal access to websites. So long as the disabled are full customers of a bank, a website that takes them into full consideration should be developed. In handling accessibility issues, people with abilities should also not be left out; they should be put into consideration as well.

In this regard therefore, this study has proven that most of the Nigerian banking websites needs to be thoroughly improved upon to consider accessibility and usability for all.

\section{REFERENCES}

[1] C.-S. Wu, F.-F. Cheng, and H.-H. Lin, "Website Usability Evaluation of Internet Banking in Taiwan," Journal of 
Internet Banking and Commerce, vol. 9, no. 1, pp. 23-36, 2004.

[2] S. Bansal, "Customer Attitude towards E-Banking Technology with Special Reference to Barnala District of Punjab," International Journal of Education and Management Engineering, vol. 2, pp. 51-58, 2017.

[3] C. Howard, "Website Usability Is A Key Factor," Usability Exchange, 2016. [Online]. Available: http://www.usabilityexchange.com/2016/02/website-usabi lity-is-a-key-factor/.

[4] A. B. Martínez, J. De Andrés, and J. García, "Determinants of the Web accessibility of European banks," Information Processing and Management, vol. 50 , no. 1, pp. 69-86, 2014.

[5] A. R. Onaolapo and E. C. Anene, "Bank Service Quality, Mobile Connectivity and Adoption of Internet Banking Among Selected University Students in Oyo State Nigeria," International Journal of Managerial Studies and Research (, vol. 4, no. 1, pp. 38-48, 2016.

[6] B. Abifarin, "How can Nigerian banks start to improve internet banking penetration?," KPMG International Cooperative, 2018. [Online]. Available: https://home.kpmg.com/ng/en/home/insights/2017/11/how -can-nigerian-banks-start-to-improve-internet-banking-pe netra.html. [Accessed: 11-Jan-2018].

[7] I. Spencer, "The Importance of Usability and Accessibility in Design," Career Foundry, 2016. [Online]. Available: https://careerfoundry.com/en/blog/ux-design/the-importan ce-of-usability-and-accessibility-in-design/. [Accessed: 11-Jan-2018].

[8] J. Mvungi and T. Tossy, "Usability Evaluation Methods and Principles for the Web," International Journal of Computer Science and Software Engineering, vol. 4, no. 7, pp. 2409-4285, 2015.

[9] B. Sohrabi, P. Mahmoudian, and I. Raeesi, "A Framework for Improving e-Commerce Websites Usability Using A Hybrid Genetic Algorithm and Neural Network System," Neural Computing and Applications, vol. 21, no. 5, pp. 1017-1029, 2011.

[10] W3C, "Web Content Accessibility Guidelines (WCAG) 2.0," 2008. [Online]. Available: https://www.w3.org/TR/WCAG20/. [Accessed: 11-Jan-2018].

[11] ISO, "ISO 9241-11:Ergonomic requirements for office work with visual display terminals (vdts)-- Part 11: Guidance on usability," ISO 9241-11: 1998, vol. 1998, 1998.

[12] K. Sheerwin, "Nielsen Norman Group University Websites : Top 10 Design Guidelines," 2016.

[13] G. Udo and M. Gerald, "Factors affecting e-commerce website effectiveness," Journal of Computer Information Systems, vol. 42, no. 2, pp. 10-16, 2002.

[14] S. G. Abduganiev, "Towards Automated Web Accessibility Evaluation : A Comparative Study," International Journal of Information Technology and Computer Science, vol. 3, pp. 18-44, 2017.

[15] J. Nielsen, "Usability 101: Introduction to Usability," Nielsen Norman Group, 2012.

[16] J. Nielsen, "10 Usability Heuristics for User Interface Design," Design Principles FTW, 2013. [Online]. Available:

https://www.designprinciplesftw.com/collections/10-usabi lity-heuristics-for-user-interface-design. [Accessed: 30-May-2018].

[17] N. Fierro and C. Zapata, "Usability Heuristics for Web Banking," in Design User Experrince and Usability, 2016, vol. 2, pp. 412-423.
[18] D. Wenham and P. Zaphiris, User Interface Evaluation Methods for Internet Banking Web Sites: A Review, Evaluation and Case Study. New Jersey: Lawrence Erlbaum Associates, 2003.

[19] E. Diniz, E. Diniz, R. M. Porto, and T. Adachi, "Internet banking in Brazil : Evaluation of functionality, reliability and usability," The Electronic Journal of Information Systems Evaluation, vol. 8, no. 1, pp. 41-50, 2014.

[20] B. Giorgio, "A comparative test of web accessibility evaluation methods," in Proceedings of the 10th international ACM SIGACCESS conference on Computers and accessibility, 2008, pp. 113-120.

[21] B. Al Mourad and F. Kamoun, "Accessibility Evaluation of Dubai e-Government Websites: Findings and Implications," Journal of E-Government Studies and Best Practices, vol. 2013, pp. 1-15, 2013.

[22] B. H. Malik, S. Cai, A. G. Mastoi, N. Gul, and H. Gul, "Evaluating Citizen e-Satisfaction from e-Government Services: A Case of Pakistan," European Scientific Journal February, vol. 12, no. 5, pp. 346-370, 2016.

[23] R. Alberto, C. Juan, M. Francisca, and B. Enrique, "Evaluation of the hotels e-services quality under the user's experience," Soft Computing, 2015.

[24] M. Y. Ivory and A. Chevalier, "A Study of Automated Website Evaluation Tools," 2002.

[25] H. Kaur and G. Gupta, "Comparative Study of Automated Testing Tools: Selenium, Quick Test Professional and Testcomplete," vol. 3, no. 5, pp. 1739-1743, 2013.

[26] A. Kaur and D. Diksha, "Banking Websites in India: an Accessibility Evaluation," CSI transactions on ICT, vol. 2, no. 1, pp. 23-34, 2014.

[27] J. Kuzma, Y. Dorothy, and O. Klaus, "Global e-Government web Accessibility: an empirical examination of EU, Asian and African Websites," in the Second International conference on Information and Communication Technologies and Accessibility, 2009, pp. 83-90.

[28] S. A. Adepoju and I. S. Shehu, "Usability Evaluation of Academic Websites Using Automated Tools," in 3rd International Conference on User Science and Engineering (i-USEr), 2014, pp. 186-191.

[29] F. J. Miranda, R. Cortés, and C. Barriuso, "Quantitative Evaluation of e-Banking Websites : an Empirical Study of Spanish Banks," The Electronic Journal Information Systems Evaluation, vol. 9, no. 2, pp. 73-82, 2006.

[30] W. Brian, J. Dung, and T. Kailee, "Exploring the accessibility of banking and finance systems for blind users," First Monday, vol. 22, no. 3, pp. 1-17, 2017.

[31] M. K. Nasir, A. Awais, and B. Muhammad, "Accessibility Evaluation of banks websites in Pakistan for disabled," in 1st International Conference on Technology Helping People with Special Needs (ICTHP-2013, 2013.

[32] J. Cappel and H. Zhenyu, "A usability analysis of company websites," Journal of Computer Information Systems, vol. 48, no. 1, pp. 117-123, 2007.

[33] R. Agarwal and V. Viswanath, "Assessing a Firms Web Presence: A Heuristic Evaluation Procedure for the Measurement of Usability," Information Systems Research, vol. 13, no. 2, pp. 168-186, 2002.

[34] A. Kaur and D. Dani, "The Web Navigability Structure of E- Banking in India," International Journal of Information Technology and Computer Science, vol. 5, no. 5, pp. 29-37, 2013.

[35] S. Kaur, K. Kaur, and P. Kaur, "Analysis of Website Usability Evaluation Methods," in Computing for Sustainable Global Development (INDIACom), 3rd International Conference on. IEEE, 2016, pp. 
$1043-1046$

[36] M. A. Aziz, W. A. R. Isa, W. mohd Isa, and N. Nordin, "Assessing the Accessibility and Usability of Malaysia Higher Education Website," in International Conference on User Science Engineering, 2010, vol. 3, no. 2008, pp. 203-208.

[37] W3C, "WAI Guidelines and Techniques," 2015. [Online]. Available: https://www.w3.org/WAI/intro/wcag.php. [Accessed: 10-Dec-2017].

[38] W3C, "Web Content Accessibility Guidelines 1.0," W3C, $1999 . \quad$ [Online]. Available: https://www.w3.org/TR/1999/WAI-WEBCONTENT-1999 0324/. [Accessed: 05-Jul-2017].

[39] W3C, "Web Content Accessibility Guidelines (WCAG) 2.0," 2008. [Online]. Available: https://www.w3.org/TR/WCAG20/\#contents. [Accessed: 07-Jul-2008].

[40] EIII, "European Internet Inclusion Initiative," EIII project, 2015. [Online]. Available: http://checkers.eiii.eu. [Accessed: 07-Nov-2017].

[41] WEBAIM, "Wave Accessibility Evaluation Tool," 2001. [Online]. Available: https://wave.webaim.org.

[42] Achecker, "Web Accessibility Checker," 2011. [Online]. Available: [Accessed: 07-Nov-2017].

[43] Pingdom, "Pingdom Website Speed Test," 2017. [Online]. Available: https://tools.pingdom.com/.

[44] Google, "PageSpeed Insights," 2017. [Online]. Available: https://developers.google.com/speed/pagespeed/insights/. [Accessed: 10-Nov-2017].

[45] "webpageFX," 2017. [Online]. Available: https://www.webpagefx.com. [Accessed: 07-Nov-2017].

[46] W3C, “Link Checker," 2011. [Online]. Available: https://validator.w3.org/checklink. [Accessed: 08-Nov-2017].

[47] P. Chris, "Web Developer," 2017. [Online]. Available: http://chrispederick.com/work/web-developer. [Accessed: 13-Oct-2017].

[48] NetApplications.com, "Market Share Statistics for Internet Technologies," NET MARKETSHARE, 2017. [Online]. Available: https://netmarketshare.com/. [Accessed: 29-Jul-2017].

[49] C. Kerri, "StatCounter.: Screen resolution alert for Web developers," statcounter GlobalStat, 2012. [Online]. Available:

http://gs.statcounter.com/press/screen-resolution-alert-forweb-developers. [Accessed: 01-Dec-2017].

[50] StatCounter, "Screen resolution alert for Web developers," 2012. [Online]. Available: http://gs.statcounter.com/press/screen-resolution-alert-forweb-developers. [Accessed: 09-Jul-2017].

[51] Toptal, "Colorblind Web Page Filter," 2017. [Online]. Available: https://www.toptal.com/designers/colorfilter. [Accessed: 11-Jan-2018].

[52] J. Bowen, "Web access to cultural heritage for the disabled," in EVA 2003 London Conference, 2003.

[53] W3C, "Web Accessibility Evaluation Tools," 2016. [Online]. Available: https://www.w3.org/WAI/ER/tools/. [Accessed: 08-Nov-2017].

[54] Google, "Test your mobile speed," 2016. [Online]. Available: https://testmysite.withgoogle.com/intl/en-gb. [Accessed: 10-Nov-2017].

\section{Authors' Profiles}

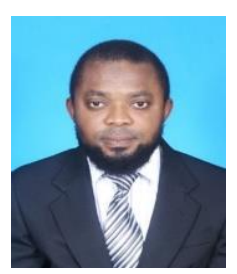

Dr. Oyefolahan I. O. is currently a Senior Lecturer at the Department of Information and Media Technology, Federal University of Technology, Minna, Nigeria. Prior to joining his current department, he was an Assistant Professor at the Department of Information Systems, International Islamic University Malaysia. His fields of interest are Business Intelligence, Web and Mobile Applications Development, Utilization and Evaluation, Business-IT Alignment and Knowledge Management. He has published several technical papers in International, National journals and conferences.

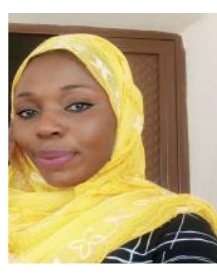

Sule Aishat Aladi is a graduate of Mathematics/Computer Science from Kogi State University Anyigba, Kogi State and currently undergoing masters of Technology in computer Science at Federal University of Technology, Minna Niger State, Nigeria. Her major area of interest is in Human Computer Interaction (HCI)

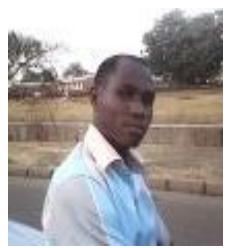

Solomon A. Adepoju holds B. Tech (Mathematics /Computer Science) and M.Sc. (Computer Science) from the Federal University of Technology, Minna and University of Ibadan respectively. Presently, he teaches in the Department of Computer Science, Federal University of Technology, Minna. He is a member many professional bodies like Computer Professional Registration Council of Nigeria (CPN), ACM, IEEE, IACST among others. His research interest includes Human Computer Interaction (website usability/accessibility), ICT4D and Multi Criteria Decision Making

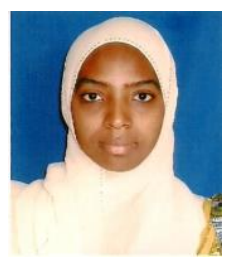

Faiza Babakano Jada is an Assistant Lecturer in the Department of Information and Media Technology, School of Information and Communication Technology, Federal University of Technology, Minna, Niger State, Nigeria. She obtained her Bsc (Computer Science) from the prestigious American University of Nigeria (2009) on full tuition scholarships and MTech (Image processing/data mining) from the Federal University of Technology, Minna in 2015. Her research interest includes Image processing, Data mining and Community and Developmental Informatics. 
How to cite this paper: Ishaq O. Oyefolahan, Aishat A. Sule, Solomon A. Adepoju, Faiza Babakano, "Keeping with the Global Trends: An Evaluation of Accessibility and Usability of Nigerian Banks Websites.", International Journal of Information Engineering and Electronic Business(IJIEEB), Vol.11, No.2, pp. 44-53, $2019 . \quad$ DOI: 10.5815/ijieeb.2019.02.06 